\title{
Epidemiological profile of acute intoxication with para- phenylenediamine (Occidental TAKAWT) in the Oriental region in Morocco: 1996-2007
}

\author{
H Rebgui $^{1}$, H Hami ${ }^{1}$, L Ouammi ${ }^{2}$, Soulaymani A ${ }^{1}$, R Soulaymani-Bencheikh ${ }^{2,3}$, \\ Mokhtari $\mathrm{A}^{1}$ \\ ${ }^{1}$ Laboratory of Genetics and Biometry, Faculty of Sciences, University Ibn Tofail, Kenitra, Morocco. \\ ${ }^{2}$ Moroccan Poison Control and Drug Monitoring Center, Rabat, Morocco. \\ ${ }^{3}$ Faculty of Medicine and Pharmacy, University Mohammed V, Rabat, Morocco.
}

\begin{abstract}
In order to reduce morbidity and mortality resulting from poisoning by para-phenylenediamine $(P P D)$, we described the epidemiological and clinical characteristics associated with such poisoning and determined the risk factors. For this purpose, we conducted a retrospective descriptive study of 102 cases reported by the Moroccan Poison Control and Drug Monitoring Center between 1996 and 2007 in the Oriental region. Based on the results, and with a sex ratio (men/women) of 0.9, the average age of the intoxicated population was $17.3 \pm 15.6$ years. The most affected group age was of adults whom age is between 20 to 74 (40.2\%). The most encountered cases were voluntary poisonings, with $91.8 \%$. Suicidal attempts had accounted for $99 \%$ of voluntary intoxication. The majority of the intoxicated had presented gastrointestinal disorders. The evolution was favorable for 87 cases $(85.3 \%)$ and 15 cases had lost their lives; the lethality was of $14.7 \%$. Following the analysis of the relative risk, age (less than 15 years / over 15 years) and origin of the intoxicated (Urban / Rural) have been the main factors that influenced the prognosis. The relative risk being, respectively, of 2.25 (95\% CI: 1, 28-3, 95) and 3, $72\left(\mathrm{CI}_{95 \%}: 1.70\right.$ - 8.13).
\end{abstract}

Keywords: Poisoning; Para-phenylenediamine (PPD); Epidemiological and clinical characteristics; Oriental; Morocco.

\section{Introduction}

The para-phenylenediamine (PPD) (Occidental TAKAWT) is a mineral product used as hair dye in several countries in Africa and the Middle East. The use of the PPD is strictly regulated in the western countries, whereas in Morocco it is freely sold by herbalists under the name of «Takaout Roumia" by analogy to a non-toxic plant product from the tamaris orientalis called «Takaout Beldia " known for its dyeing qualities. [1] The wide use of the PPD has led to the discovery of its toxic effects. Taken orally, it is at the origin of a severe intoxication that can be fatal despite therapeutic measures. In Morocco, it is the leading cause of autolysis poisoning. Indeed, when orally absorbed, it first causes a respiratory distress that threatens the prognosis, associated with rhabdomyolysis and acute renal failure [2].

PPD poisoning has become a health problem in Morocco as it is responsible for significant mortality rate in young patients $[3-4]$

This retrospective study went through all registration forms and medical records of paraphenylenediamine poisoned patients through 11 years (102 cases). The aim of this study is to determine the demographic, clinical and evolutive characteristics of PPD poisoning recorded in the Oriental region and identify the factors associated with the severity of this type of poisoning, improve the management of this problem and reduce the morbidity and mortality caused by this product.

\section{Data and methods}

The present work is a retrospective descriptive study of of 102 cases of poisoning by paraphenylenediamine in the oriental region as reported by the Moroccan Poison Control and Drug Monitoring Center over a period of 11 years, from January 1996 to December 2007.

The Oriental region is located in the east of Morocco. It is bordered by Algeria to the east, the Mediterranean Sea to the north and the region of Taza-Al Hoceima-Taounate and Fez-Boulemane to the west (Fig 1). According to the Moroccan General Census of (2004), its area is $82,820 \mathrm{~km}^{2}$ and its population is of $1,918,094$ [5]. 
Poisoning reports that were regularly received by medical facilities of the Moroccan Poison Control and Drug Monitoring Center in the oriental region filled by the physicians in charge of the cases, or, if not present, by the nurses, and medical records filled by telephone using the data given by the Toxicological Information Unit doctor of the MPCDM were both entered on a single database and then processed.

The methodology is based on a description of the sample. The description concerned the spatiotemporal parameters (year, province, origin), the characteristics of intoxicated patient (sex, age, ethnicity), characteristics of the toxic (product family involved) and characteristics of poisoning (type intoxication, circumstances, symptoms, treatment, gradation and evolution). Assessing the seriousness of the condition (grade) was performed according to the "poisoning severity score" [6]. Age was analyzed according to the INTOX classification. The $\chi^{2}$ test was used to shed light on whether a difference between variables is significant. The calculation of the relative risk tells us about the connection of various factors with the outcome of poisoned patients.

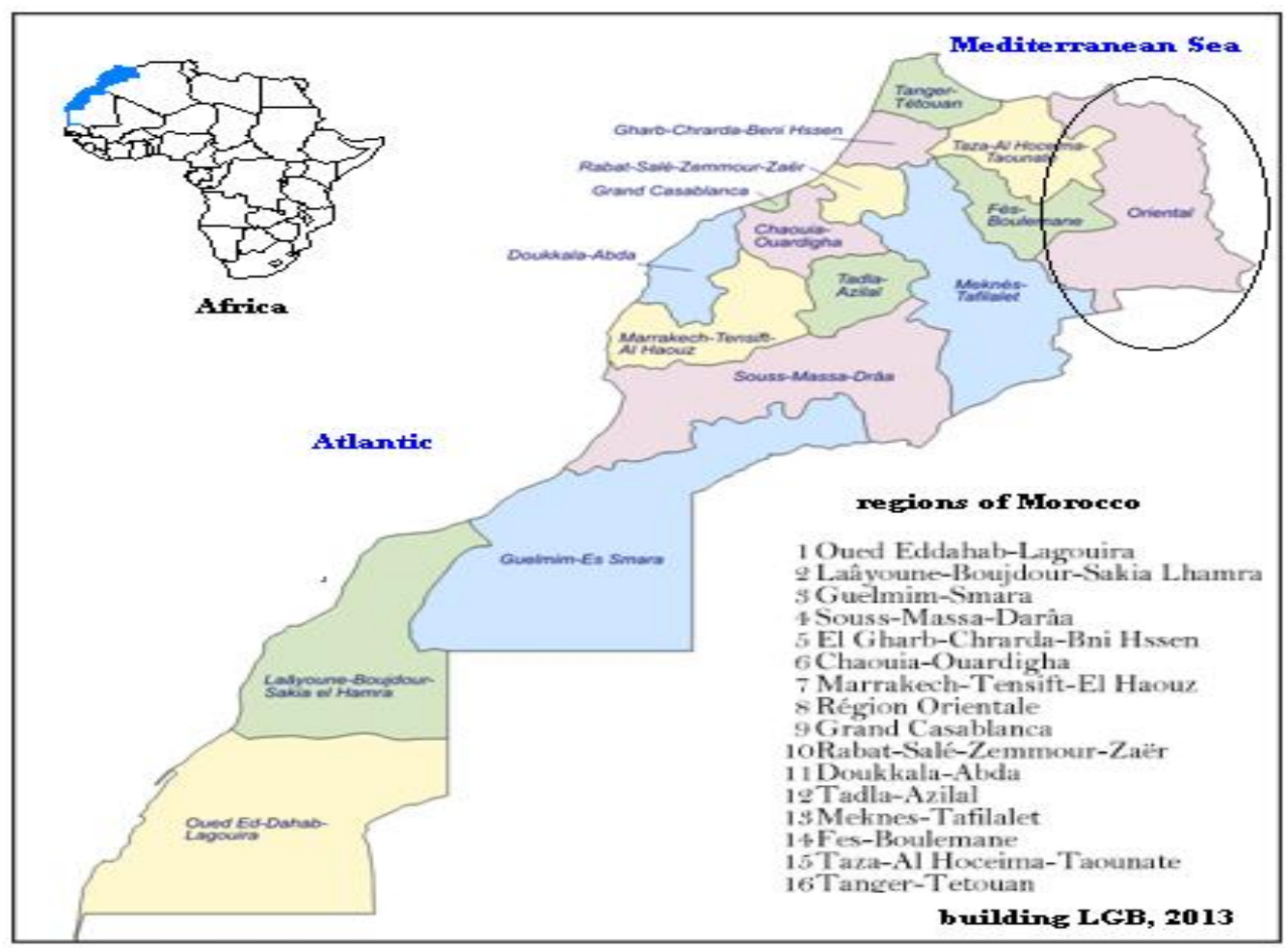

Fig. 1: Geographical position of Oriental region, Morocco

\section{Results}

\section{a. Epidemiological an clinical Profile of poisonings in the region of the Oriental}

The results for the distribution of poisoning cases according to the studied parameters are shown in the table I. The province of Oujda-Angad had reported the greatest number of intoxication (72.5\%), followed by the provinces of Nador (17.6\%), Taourirt (5, 9\%), Jerada (2\%), Figuig (1\%) and Berkane (1\%). The majority of the reports $(95.7 \%$ of the cases) came from the urban area.

The age group most at risk was that of adults whom age is between 20 and 74 (40.2\%), followed by baby walkers [1-4 years old] (24.5\%) and children [5-14] (15.4\%). The average age of the affected people is $17.3 \pm 15.6$ years. A female predominance was noted $(82.4 \%)$, with a sex- ratio $(\mathrm{M} / \mathrm{F})$ of 0.2 . specific lethality for man was higher $(22,22 \%)$. Most cases $96.7 \%$ came from a home environment. Most of the poisoned $(88.2 \%)$ presented clinical signs- The most clinical signs were answered digestive and respiratory and cardiovascular signs represented $51.8 \%$ and $32.6 \%$ 8.8\% respectively of total signs-. The intoxication was voluntary in $91.8 \%$ of the cases with a very high specific lethality $(15.73 \%)$. Suicidal attempts had accounted for $99 \%$ of voluntary intoxication.

Of the 4330 cases for which the outcome was known, 4,240 cases had evolved favorably and 66 cases had died, (hence a fatality rate of $1.5 \%$ ). The evolution was favorable for 87 cases $(85.3 \%)$ and 15 cases had lost their lives; the lethality rate was of $15 \%$.

The main epidemiological variables are shown in table I. 
Table I: Description of the epidemiological characteristics of the population sample

\begin{tabular}{|c|c|c|c|c|c|c|c|c|}
\hline \multirow{2}{*}{\multicolumn{2}{|c|}{ Variable }} & \multicolumn{2}{|l|}{ Global } & \multicolumn{4}{|c|}{ Evolution } & \multirow[t]{2}{*}{ Specific Lethality } \\
\hline & & $\begin{array}{l}\text { Number } \\
(\mathrm{N}=102)\end{array}$ & $\%$ & & $\begin{array}{c}\text { Cured } \\
(\mathrm{N}=87)\end{array}$ & & $\begin{array}{l}\text { Death } \\
(\mathrm{N}=15)\end{array}$ & \\
\hline \multicolumn{9}{|c|}{ Province } \\
\hline & Oujda Angad & 74 & 72.5 & 60 & & 14 & & 18.92 \\
\hline & Nador & 18 & 17.6 & 17 & & 1 & & 5.56 \\
\hline & Jerada & 2 & 2 & 2 & & - & & - \\
\hline & Taourirt & 6 & 5.9 & 6 & & - & & - \\
\hline & Figuig & 1 & 1 & 1 & & - & & - \\
\hline & Berkane & 1 & 1 & 1 & & - & & - \\
\hline & Unknown & - & - & - & & - & & \\
\hline & Total & 102 & 100 & 87 & & 15 & & \\
\hline \multicolumn{9}{|c|}{ Age Groups } \\
\hline$\bullet$ & New born & - & - & - & & - & & - \\
\hline$\bullet$ & Infant & 7 & 6.9 & 7 & & - & & - \\
\hline$\bullet$ & Baby walker & 25 & 24.5 & 21 & & 4 & & 16.00 \\
\hline$\bullet$ & Child & 19 & 18.6 & 15 & & 4 & & 21.05 \\
\hline$\bullet$ & Teenagers & 10 & 9.8 & 8 & & 2 & & 20.00 \\
\hline$\bullet$ & Adult & 41 & 40.2 & 36 & & 5 & & 12.20 \\
\hline$\bullet$ & Elderly Person & - & - & - & & - & & - \\
\hline$\bullet$ & Unknown & - & - & - & & - & & - \\
\hline$\bullet$ & Total & 102 & 100 & 87 & & 15 & & - \\
\hline \multicolumn{9}{|l|}{ Sex } \\
\hline . & Male & 18 & 17.6 & 14 & & 4 & & 22.22 \\
\hline & Female & 84 & 82.4 & 73 & & 11 & & 13.10 \\
\hline & Unknown & - & - & - & & - & & - \\
\hline & Total & 102 & 102 & 87 & & 15 & & - \\
\hline \multicolumn{9}{|l|}{ Origin } \\
\hline & Urban & 90 & 88.2 & 77 & & 13 & & 14.44 \\
\hline & Rural & 4 & 3.9 & 3 & & 1 & & 25.00 \\
\hline & Unknown & 8 & 7.8 & 7 & & 1 & & - \\
\hline & Total & 102 & 100 & 87 & & 15 & & - \\
\hline \multicolumn{9}{|c|}{ Circumstances } \\
\hline & Accidental & 8 & 7.8 & 8 & & 1 & & 12.50 \\
\hline & Voluntary & 89 & 87.3 & 76 & & 14 & & 15.73 \\
\hline & Unknown & 5 & 4.9 & 3 & & - & & - \\
\hline & Total & 102 & 100 & 87 & & 15 & & - \\
\hline \multicolumn{9}{|c|}{ Type of intoxication } \\
\hline & Home & 88 & 86,3 & 76 & & 12 & & 13.64 \\
\hline & Outdoor & 3 & 2.9 & 2 & & 1 & & 33.33 \\
\hline & Unknown & 11 & 10.8 & 9 & & 2 & & - \\
\hline 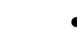 & Total & 102 & 100 & 87 & & 15 & & - \\
\hline \multicolumn{9}{|c|}{ Clinical } \\
\hline & Asymptomatic & 12 & 11.8 & 11 & & 1 & & 8.33 \\
\hline & Symptomatic & 90 & 88.2 & 76 & & 14 & & 15.55 \\
\hline & Unknown & - & - & - & & - & & - \\
\hline - & Total & 102 & 100 & 87 & & 15 & & - \\
\hline \multicolumn{9}{|l|}{ Grade } \\
\hline . & Grade 0 (None) & 35 & 34.3 & 3 & & - & & - \\
\hline & Grade1 (minor) & 1 & 1.0 & 1 & & - & & - \\
\hline & Grade2 (Moderate) & 24 & 23.5 & 24 & & - & & - \\
\hline & Grade3 (Severe) & 27 & 26.5 & 27 & & - & & - \\
\hline & Grade4 (Fatal) & 15 & 14.7 & - & & 15 & & 100 \\
\hline & Unknown & - & - & 32 & & - & & - \\
\hline . & Total & 102 & 102 & 87 & & 15 & & - \\
\hline
\end{tabular}

The below table shows the distribution of intoxication cases according to treatment among 86 cases, we noted that the most frequently used treatments in PPD poisoning are symptomatic treatment $(44,2 \%)$, Therapeutic Abstention (36\%) and the spillway treatment (19.8\%) (Table II). 
Table II: Distribution of the intoxicated according to the adopted treatment

\begin{tabular}{|c|c|c|c|c|c|}
\hline Treatment & $\begin{array}{l}\text { Number } \\
(\mathrm{N}=102)\end{array}$ & $\%$ & Inder treatment & $\begin{array}{l}\text { Numb } \\
\text { er }\end{array}$ & $(\%)$ \\
\hline Therapeutic & 31 & 30.4 & - & & \\
\hline \multicolumn{6}{|l|}{ Abstention } \\
\hline & & & & - & - \\
\hline Symptomatic & & & - & - & - \\
\hline treatment & 38 & 37.3 & & & \\
\hline \multirow[t]{3}{*}{ Spillway Treatment } & & & induced & & \\
\hline & 17 & 16.7 & vomiting & 1 & 7.9 \\
\hline & & & lavage & 16 & 87.3 \\
\hline Unknown & 16 & & & & \\
\hline Total & 102 & 15.7 & & & \\
\hline & & 100 & & & \\
\hline
\end{tabular}

\section{b. Factors influencing the vital prognosis of patients}

$\square^{2}$ for independence and the relative risk are calculated to identify risk factors that have affected the evolution of poisoned patients in our sample. It reflects the effect with respect to the basic frequency of the event. The purpose of a relative measure is to achieve an adjustment on the initial value and therefore obtain an independent measure of this one.

The results reported in Table III show the characteristics that may indicate a significant modality over others with respect to different studied characteristics.

Table III: Severity factors affecting patient progress

\begin{tabular}{|c|c|c|c|c|c|}
\hline Variabl & & $\begin{array}{l}\text { Number } \\
\text { Of cured } \\
(\mathrm{N}=87) \\
\end{array}$ & $\begin{array}{l}\text { Number of } \\
\text { Deaths }(\mathrm{N}=15)\end{array}$ & $\mathbf{R R}$ & IC $95 \%$ \\
\hline \multicolumn{6}{|l|}{ Origin } \\
\hline & Rural & 3 & 1 & \multirow{5}{*}{0.54} & \multirow{5}{*}{$0,45-1,96$} \\
\hline & & & & & \\
\hline & Urban & 77 & 13 & & \\
\hline & Unknown & 7 & 1 & & \\
\hline & Total & 87 & 15 & & \\
\hline \multicolumn{6}{|c|}{ Sex } \\
\hline & Male & 14 & 4 & \multirow{5}{*}{2.18} & \multirow{5}{*}{$1,41-3,37$} \\
\hline & & & & & \\
\hline & Female & 73 & 11 & & \\
\hline & Unknown & - & - & & \\
\hline & Total & 87 & 15 & & \\
\hline \multicolumn{6}{|l|}{ Age } \\
\hline & $\begin{array}{l}\text { Children } \\
\text { years })\end{array} \quad(<=15$ & 43 & 8 & \multirow[t]{4}{*}{0.34} & \multirow[t]{4}{*}{$0,06-1,77$} \\
\hline & Adult (>15 years) & 44 & 7 & & \\
\hline & Unknown & - & & & \\
\hline & Total & 87 & & & \\
\hline \multicolumn{6}{|c|}{ Location of intoxication } \\
\hline & Outdoor & 2 & 1 & & \multirow{4}{*}{$1,29-2,83$} \\
\hline & Home & 76 & 14 & \multirow[t]{3}{*}{1.91} & \\
\hline & Unknown & 9 & - & & \\
\hline & Total & 87 & 15 & & \\
\hline \multicolumn{6}{|c|}{ Circumstances } \\
\hline & Voluntary & 76 & 14 & \multirow{4}{*}{0.44} & \multirow{4}{*}{$0,28-0,68$} \\
\hline & Accidental & 8 & 1 & & \\
\hline & Unknown & 3 & - & & \\
\hline & Total & 87 & 15 & & \\
\hline \multicolumn{6}{|c|}{ Clinical Status } \\
\hline & Symptomatic & 76 & 14 & \multirow{3}{*}{0.51} & \multirow{3}{*}{$0,36-0,74$} \\
\hline & & & & & \\
\hline & Asymptomatic & 11 & 1 & & \\
\hline
\end{tabular}


RR Relative Risk - $95 \%$ CI: $95 \%$ Confidence Interval - $\mathrm{p} \geq 0.05$ : non significant link $-0.01<\mathrm{p}<0.05$ : significant link $(5 \%)-0.001<\mathrm{p}<0.01$ : very significant link $(1 \%)-\mathrm{p}<0.001$ : highly significant link $0,1 \%)$.

In light of the above table, the patient's sex and place of intoxication were risk factors associated with death. Men were twice as likely as women exposed to death ( $R R=2.18$, [1.41 to 3.37]), this due to the use PPD for suicidal purposes. Those intoxicated in public places were twice exposed to death as those intoxicated at home (Table III).

\section{Discussion}

The Moroccan market has since 1970 a PPD based mineral product that has taken the place of the common Takaout beldia. This product has not only remarkable dyeing qualities, but also high availability at low cost and the quality of imported product. This earned it, by extension, the name of Takaout Roumia [3].

The experimental toxicity of the PPD has been known for a long time, the first tests were conducted by Dubois and Vignon in 1898, when cases of human intoxication were rare in the west.

In 1924, Nott described the first case of systemic PPD poisoning in a hair salon owner who was handling hair dye. Since, other cases were reported [3-4]. In France, cases have been reported by F. Baud [7] in a Moroccan family.

Other cases have been described in Sudan [3] and Tunisia [8]. In Morocco, the first reported case dates to 1978 and since, several reports have been successively recorded [9-10].

Since 1980, there has been a significant increase in this type of intoxication. [2], published a series of 315 patients collected over five years at the CHU of Casablanca, the average age was 23, with a female predominance (91\%), most took PDD with an autolysis goal 93\%. This type of intoxication is the most common in the Moroccan society in comparison to European countries where drug poisoning remain the most frequent [11]. In our study PPD poisoning accounted for $26 \%$ of acute poisonings while compared with all the other products.

PPD intoxication can affect any age group, but the young are the most affected. In our series, adults [20-74 years] were the most affected with $40 \%$ of the cases, baby-walkers accounted for $28 \%$. This could be explained by the ignorance of the Moroccan families to the risks of PPD, this latter can be fatal if the poisoned child is not taken care of correctly. This result corroborated with that of Bensalma and al who demonstrated that PPD poisonings are observed especially among young people aged between 15 and 35 [12]. Observations have been reported in infants and children. In our study, a female predominance has been noted (82\%). This predominance is reported by most publications about PPD poisoning [1- 7- 8].

For most studies ingestion is done with an autolysis goal. In addition to its use for suicide, crime or even abortion, it also reported to be used as a remedy against pain Averbukh [13], or against constipation Schemesh [14], still, its autolysis use is the most predominant. Voluntary intoxication with an autolysis goal is the most prominent in Casablanca with almost $90 \%$ of cases [12]. In our series, intoxication was voluntary in $91 \%$ of the cases. Suicidal attempts had accounted for $99 \%$ of voluntary intoxication.

Oral intake was the most frequent (89\%). The same result was reported by A Benselma et al. on a national scale study which demonstrated that oral intake was the most suspected, whereas the dermal cases of PPD poisoning were reported by local application on the scalp and caused systemic poisoning. The passage in the blood of the PPD would be in report with lesions of the scalp. In professional pathology allergic dermatitis were observed [12].

The most frequent clinical signs were digestive, respiratory and cardiovascular representing respectively $52 \%, 33 \%$ and $8 \%$ of the total of all signs. A study in Morocco on 24 cases demonstrated the occurrence of certain gastrointestinal symptoms such as epigastric pain, vomiting and, in 13 cases, nausea (56\%) [15]. According to another study on PPD poisoning in Morocco, the clinical results were dominated by respiratory distress represented by a typical head and neck edema. This edema is located in the beginning of the head and neck region, the pharynx and extends to the larynx. Lysis of the heart muscle due to PPD, proven experimentally, has been the subject of recent studies that have been focusing on a new clinical aspect of these poisonings, an aspect that remains underestimated and poorly documented [16]. Kerkeb et al. reported in 1998, two cases of myocarditis in 95 cases of PPD poisoning collected between 1983 and 1997 [17]. The myocarditis diagnosis was based on clinical, electrical, ultrasound and histological signs. In another publication, Ababou et al. reported a cas of myocarditis after PPD intoxication was confirmed by histological study [18].

Acute PPD poisoning is currently the first cause of hospital emergency consultation in the developed countries. Taking care for an acutely intoxicated is therefore a frequent problem [12].

Due to the lack of an antidote for PPD poisoning, the treatment is purely symptomatic and based on spillway treatment, the treatment of edema and the acute respiratory distress [19]. 
The lethality of PPD poisonings is high in our serie $(15 \%)$. This result is seen in a study which has been carried out in all the regions of Morocco, this is due to the delay in medical consultation mainly because to geographical remoteness to our hospital structure, as well as the unfavorable socio-economic status of our patients. In addition, the ignorance by medical personnel to the clinical effects of PPD and therapeutic bases of these poisonings as evidenced by the often inadequate prescriptions especially in emergency services [12].

\section{Conclusion}

This study gave an overall idea on PPD poisoning in the Oriental region. The analysis helped to assess and monitor changes in the spatio-temporal characteristics, and the characteristics relating to the intoxicated, the toxic and intoxication. Suicidal poisonings were frequent with an alarming number.

The commercial availability of the product in its pure form is very alarming, and justifies the use of a wide prevention program to inform the public and the authorities of the danger of PPD.

The ban on the import and sale of pure PPD or in combination with other dyes and regulation of it's industrial use is urgent. On the medical side, the intoxicated must be taken care of immediately in intensive care units. this intoxication.

In addition, health professionals need to be familiar with the clinical picture and the potential danger of

\section{References}

[1] H Yagi, AM El Hendi. Acute poisoning from hair dye. East Afr Med J, 18(2), 1991, 68-404

[2] S Moutaouakkil, B Charra, A Hachimi, H Ezzouine, H Guedari, H Nejmi H and A Benslama.. Rhabdomyolyse et intoxication à la paraphénylène-diamine. Ann Fr Anesth Réanim, 25(3), 2006, 708-713

[3] M Sir Hashim, YO Hamza, B Yahia, FM Khogali and GI Sulieman. Poisoning from henna dye and paraphenylene diamine mixtures in cheldren in khartoum. Ann Trop Paediatr, 12(1), 1992,3-6

[4] FJ Baud, M Gaillot, JP Cantineau, J Muszinski, A Bolo, T Benahmed,and Bismuth C. Rhabdomyolyse au cours d'une intoxication aigue par la paraphénylène diamine. Journal de toxicologie Médicale, 56(4), 1984, 279-283

[5] Haut Commissariat au plan (Maroc), Recensement général de la population et de 1'habitat de 2004, Caractéristiques démographiques et socio-économiques : région de l'Oriental, 8, 2004.

[6] H.E Person, H.E Sjöberg and Haines. J.A. Poisoning Severity Score. Grading of Acute Poisoning. Clinical Toxicology. 36(3), $1998,205-213$

[7] FJ Baud, C Bismuth, M Gaillot, R Garnier and A Peralma. Rhabdomyolysis in para-phenylenediamine intoxication. The lancet, 2 (8) $1983,248-250$

[8] H Kallel, H Chelly, H Dammak, M Bahloul, H Ksibi and CB Hamida. Clinical manifestations of systemic paraphenylenediamine intoxication. J Nephrol, 18(3), 2005, 8-11.

[9] A Bourquia, A Jabrane, B Ramdani and D Zaid. Toxicité systémique de PPD. Presse Med. 17(35), 1988, 798-800

[10] A Zeggwagh, R Abouqal and N Madani. Myocardite toxique due à l'intoxication au paraphénylène-diamine: A propos de deux cas. Reanim Urg, 5(1), 1996, 699-703

[11] Villa A, Baud FJ, Megarbane B, Lapostolle F, Garnier R, Bismuth C. Intoxications aigues les plus fréquentes. Encycl. Méd.

[12] A BENSLAMA, A HACHIMI, B CHARRA, S MOTAOUAKKIL. L'intoxication à la paraphénylène-diamine au Maroc. 81(Casablanca, 2008) 767-780.

[13] Z Averbukh, D Modai, and Y Leonov. Rhabdomyolysis and acute renal failure induced by PPD. Human toxical, 8(2), 1989, 345348

[14] I Shemsh, Y Mishal, A Baruchin and R Viskoper. Rhabdomyolysis in PPD intoxication. Vet Hum Toxicol. , 37(3), 1995, 244-5

[15] A Derkaoui, L Labib, S Achour, H Sbai, M Harrandou, M Khatouf and N Kanjaa. Intoxication par la paraphényléne-diamine (takaout) au Maroc: à propos de 24 cas. Pan Afr Med J. 4(1), 2011, 8-19.

[16] R Munday, E Manns and EA Fowke. Muscle necrosis by N-methylated PPD in rats: structure activity relationships and correlation with free-radical production in vitro. Toxicology, 57 (4), 1989, 14-30

[17] O Kerkeb, AA Zeggwagh, R Abouqual, N Madani, A Zerkaoui. Myocardite toxique secondaire à l'intoxication aiguë par la paraphénylène diamine. Ann Fr Anesth Réanim, 17(1) 1998, 10-59

[18] Ababou A, Ababou K, A Mosadik, C Lazreq and A Sbihi. Rhabdomyolyse du myocarde après intoxication par la paraphénylène diamine. Ann Fr Anesth Réanim. 19(5) 2000 ; 7-10.

[19] W Ashraf, S Dawling, LJ Farrow. Systemic para phenylenediamine(ppd) poisoning: acase report and review. Human and experimental toxicology, 13 (7), 1994, 7-16 